\title{
Silver Nanoparticles - Green Synthesis with Aq. Extract of Stems Ip- omoea Pes-Caprae, Characterization, Antimicrobial and Anti-Can- cer Potential
}

\section{Subha Veeramani ${ }^{2}$, Ernest Ravindran $R^{2}{ }^{2}$, Preethi Ramadoss ${ }^{3}$, Cyrril Joseph ${ }^{4}$, Kirubanandan Shan- mugam $^{1^{*}}$ and Renganathan $S^{1}$}

\author{
${ }^{1}$ Department of Biotechnology, A. C. Tech, Anna University, India \\ ${ }^{2}$ Department of Electronics and Communication Engineering, $K$ L University, India \\ ${ }^{3}$ Crystal Growth Centre, A. C. Tech, Anna University, India \\ ${ }^{4}$ Department of Chemical Engineering, A. C. Tech, Anna University, India
}

*Corresponding author: Subha Veeramani and Kirubanandan Shanmugam, Department of Biotechnology, A. C. Tech, Anna University, India

\begin{abstract}
Green synthesis is a novel process for the preparation of numerous metallic nanoparticle and provides a safer and eco-friendly process simultaneously achieving functionalization of nanoparticles with bioactive molecules in the plants extract. Green synthesis of silver nanoparticles (AgNPs) is performed using the aqueous extract of Ipomoea pes-caprae stems which acts as a bio-reducing agent. UV spectroscopic investigation confirms the formation of AgNPs by noticing the peak at $448 \mathrm{~nm}$ due to its surface plasmon resonance effect. The FTIR spectrum notifies peaks at 640 , 3535, 3217, 1660, $1043 \mathrm{~cm}^{-1}$ confirming AgNPs mixing with the plant extract during synthesis. XRD analysis of AgNPs represents the (1 03 3), (1 111 1), (2 20 ) and (3 11 1) Bragg's reflections confirming FCC structure of silver in the nanoparticles. Transmission electron microscopic (TEM) investigation reveals non-agglomerated, well-dispersed AgNPs maintain its spherical shape and the size mostly less than $100 \mathrm{~nm}$. AgNPs synthesized from Ipomoea pes-caprae plant extract were found to be in nano size and stable. The antibacterial potential of AgNPs against clinical isolates, such as $P$. aeruginosa, E. coli and Bacillus shows $13 \pm 2 \mathrm{~mm}, 19 \pm 2 \mathrm{~mm}$, $14 \pm 1 \mathrm{~mm}$ zone of inhibition respectively with the $100 \mu \mathrm{g}$ of AgNPs. The MTT assay confirms the anticancer potential of AgNPs from Ipomoea pes-caprae stem extract showing IC 50 values of $78 \mu \mathrm{g}$ of AgNPs/ml against MCF-7 cancer cells and cytotoxic effects raises AgNPs layers with the plant extract giving anti-proliferative effects on the cancer cells. This work suggests functionalizing AgNPs with plant extract, an alternative chemotherapeutic and anti-bacterial agent via a green synthesis approach.
\end{abstract}

\section{Keywords}

Ipomoea pes-caprae, Silver nanoparticles, Anti-microbial, Anti-cancer, MCF-7

\section{Introduction}

Metallic nanoparticles offer high reactivity and selectivity owing to its large surface to volume ratio and used in designing drug delivery vehicles and targeting. Silver nanoparticle is the most predominant in metallic nanoparticles and plays an outstanding contribution in numerous fields such as medicine, water purification, food packing, personal care, indoor air quality management, catalysis, environmental pollution control [1] etc., AgNPs especially known for its high specific surface area and their potential in treating various health disorder like Retinal Neovascularization, Hepatitis-B, Cancer, Diabetes and Human Immunodeficiency Virus etc., in near future [2-5]. AgNPs with high surface-volume ratio exhibit various surface charging characteristics scenario (positive, neutral and negative) [6] and tailoring its surface used in drug delivery and targeting. Synthesis of AgNPs is a complex process of oxidizing of reduced silver and its complex interaction with various stabilizers. Silver nanoparticles (AgNPs) were synthesized by common techniques namely chemical reduction with/

Citation: VeeramaniS, Ernest RRS, Ramadoss P, Joseph C, Shanmugam K, et al. (2018) Silver Nanoparticles - Green Synthesis with Aq. Extract of Stems Ipomoea Pes-Caprae, Characterization, Antimicrobial and Anti-Cancer Potential. Int J Med Nano Res 5:024. doi.org/10.23937/2378-3664/1410024

Accepted: October 08, 2018: Published: October 10, 2018

Copyright: (C) 2018 Veeramani S, et al. This is an open-access article distributed under the terms of the Creative Commons Attribution License, which permits unrestricted use, distribution, and reproduction in any medium, provided the original author and source are credited. 
without stabilizing agents [7], organic solvents by thermal decomposition [8], photo-reduction method in reverse micelles $[9,10]$, and radiation chemical reduction [11-13]. These are extremely expensive and involving hazardous chemicals which leads to a complex synthesis and not up-scalable.

Metallic nanoparticles were recently synthesized via green synthesis to develop environmentally friendly processes with less usage of chemicals that led to the synthesis of metallic nanoparticles by bioreduction mechanism. Biologicals such as, enzymes, fungus and plant extracts are few possible ecofriendly and less expensive compared to that of others previous methods of AgNPs [7-13].

Ipomoea pes-caprae known as beach morning glory that is a creeping vine belonging to the family Convolvulaceae. It is a salt tolerant plant widely distributed in various parts of the world. AgNPs synthesized biologically with aqueous stem extract of Ipomoea pes-caprae is a cost effective and eco-friendly approach and used to cure urinary or kidney complications, hypertension and mycobacterium for tuberculosis, skin infections. This plant leaf decoctions also used to treat the digestive tract disorders, severer colic, internal pain, dysentery, rheumatism and other inflammatory conditions [14-16]. Ipomoea pes-caprae (IP) possess anti-nociceptive, anti-haemolytic, anti-spasmodic, anti-histamine, anti-cancer, antioxidant, anticancer, antihistaminic, insulogenic and hypoglycemic activities $[17,18]$.

Recently, the antitumor potential of IP against melanoma cancer (B16F10) in male C57BL mice was explored and confirmed the antitumor potential of $I$. pes-caprae on skin cancer cells. Betulinic acid isolated from I. pescaprae was identified as a highly selective growth inhibitor against human melanoma and non-melanoma also malignant tumor cells and further, it was reported to induce apoptosis in numerous cancer cell lines both in vivo and in vitro. The bioactive constitutes of IP are essential oils such as limonene, $\alpha$-terpineol, $\alpha$-humulene, $\alpha$-thujene, $\alpha$-pinene, eugenol, and $\beta$-myrcene reported for their cytotoxic activity. The antitumor effect of $I$. pes-caprae is due to its essential oil component in the extract. The partial antitumor effect of $I$. pes-caprae may be attributed to the presences of these essential oil components present in its leaves. Further, the anti-tumor activity of the aqueous extract of IP is quite potent than that of petroleum ether extract and the aqueous extract of IP contains many polar bioactive compounds such as alkaloids, flavonoids, tannins, terpenoids, and glycosides. These compounds are potent anti-tumor agents [19]. Therefore, the aqueous extract of this plant is used to biosynthesize the silver nanoparticles.

This paper investigates involving the stem of this medicinal plant in green synthesis of silver nanoparticles (AgNPs) and characterizing and evaluating antimicrobial and anti-cancer potential of nanoparticles.

\section{Materials and Methods}

\section{Preparation of stem extract}

The stems of Ipomoea pes-caprae were collected from beach of Besant Nagar, Chennai, India. Fresh stem of Ipomoea pes-caprae were surface cleaned using distilled water and followed washing with double distilled water and then chopped into pieces of $5 \mathrm{~mm}$. Chopped pieces were dried at room temperature and grinded to fine powder using mechanical grinder. Fine powder of $5 \mathrm{~g}$ was weighed and dissolved in $100 \mathrm{ml}$ of Millipore water and stirred vigorously under $60^{\circ} \mathrm{C}$ for about 20 $\mathrm{min}$. Then the mixed solution was cooled to room temperature then filtered using Whatman No 1 filter paper and the filtrate was collected and stored [20].

\section{Synthesis of silver nanoparticles (AgNPs)}

$20 \mathrm{ml}$ of aqueous stem extract of Ipomoea pes-caprae was added drop by drop into the $1 \mathrm{mM}$ of $\mathrm{AgNO}_{3}$ solution. The colorless silver nitrate solution turns to brown color that indicates the formation of AgNPs. Then the solution was stirred at $50^{\circ} \mathrm{C}$ for $3 \mathrm{~h}$ and then centrifuged at 12,000 rpm for $15 \mathrm{~min}$ and was repeated 3 times with intermediate washing with Millipore water. The obtained suspension was stored as product for future characterization and anti-cancer evaluation after lyophilization.

\section{Characterization of AgNPs}

\section{UV analysis}

The silver ion reduction was monitored by measuring the UV-visible spectrum of the reaction medium after diluting the solution to a range between $200-900 \mathrm{~nm}$ UV-visible Spectrophotometers. The UV-visible spectra were recorded by a UV-visible JascoV-550 spectrophotometer.

\section{FTIR investigation}

To study the Ag nanoparticle and its associating molecules, FTIR measurements were carried out for both plant extract and the as prepared silver nanoparticles. The AgNPs were centrifuged at $9000 \mathrm{rpm}$ for $30 \mathrm{~min}$. The AgNPs were dried and ground with potassium bromide to form a pellet and analyzed on Jusco 5300 FTIR Instrument with a range of $400-4000 \mathrm{~cm}^{-1}$.

\section{$\mathrm{X}$-ray diffraction studies}

This study used to evaluate the structure of AgNPs and its lattice and was made on the powder samples at room temperature of $27^{\circ} \mathrm{C}$ on a Rigaku X-ray diffractometer (Miniflex, UK).

\section{Dynamic scattering of AgNPs}

Dynamic Scattering of AgNPs is performed with an instrument DLS Malvern instrument which investigates the average size of the particles, size distribution, and polydispersity index (PDI) of the silver nanoparticles from green synthesis. 


\section{TEM investigation on AgNPs}

The TEM analysis was carried out to determine the shape and the mean particle size of nanoparticles. The sample were prepared on a carbon coated grid by just dipping a very small amount of the prepared AgNPs on the grid, by using blotting paper the extra solution was isolated. The TEM analysis was done using HITA$\mathrm{CHI} \mathrm{H-7650} \mathrm{at} \mathrm{an} \mathrm{operating} \mathrm{voltage} \mathrm{of} 80 \mathrm{kV}$.

\section{Anti-microbial activity of AgNPs}

Nutrient agar medium was autoclaved to sterilization and transferred to petri plate to solidify. After that solidification, fresh growth of clinical isolates were inoculated, then AgNPs with various concentrations were loaded, $25 \mu \mathrm{g}, 50 \mu \mathrm{g}, 75 \mu \mathrm{g}$ and $100 \mu \mathrm{g}$, respectively. The antibacterial assay plates were measured after the $24 \mathrm{~h}$ incubation at $37^{\circ} \mathrm{C}$.

\section{Anti-cancer activity of AgNPs}

The MTT assay was performed as per the protocol slater, et al. [21]. In brief, Yellow MTT (3-(4, 5-Dimethylthiazol-2-yl)-2, 5-diphenyltetrazolium bromide, a tetrazole) is reduced to purple formazan in the mitochondria of living MCF-7 cells. The cells in T-25 flask are trypsinized and $5 \mathrm{ml}$ of Dulbecco's Modified Eagle's medium (DMEM) is added to the trypsinized cells. A sterile $15 \mathrm{ml}$ falcon tube is centrifuged at $1000 \mathrm{rpm}$ for 5 min. The media is discarded, and cells are resuspended into $1 \mathrm{ml}$ with newly prepared and sterilized media. The cells per $\mathrm{ml}$ are counted and then the cells are diluted to 50,000 cells per ml. DMEA media is used to dilute cells. $100 \mu \mathrm{l}$ of cells ( 5000 total cells) are added into each well and incubated for $24 \mathrm{~h}$. Cells are treated with different concentration of AgNPs after $24 \mathrm{~h}$. Final volume should be $100 \mu \mathrm{l}$ per well and incubated for next $24 \mathrm{~h} .20 \mu \mathrm{l}$ of $5 \mathrm{mg} / \mathrm{ml} \mathrm{MTT}$ is added to each well. A set of wells with MTT without cells is considered as control and then incubated for $4 \mathrm{~h}$ at $37^{\circ} \mathrm{C}$ in culture hood and then discarded the media. $150 \mu \mathrm{l}$ MTT solvent (DMSO) is added and covered with tinfoil and agitated cells on orbital shaker for $15 \mathrm{~min}$. The absorbance at $590 \mathrm{~nm}$ is read with a reference filter of $620 \mathrm{~nm}$.

\section{Statistical evaluation}

All the experiments were carried out in triplicates and the data are statistically significant via performing descriptive statistics in MS-Excel-2010. The data are expressed with standard deviation.

\section{Result and Discussions}

\section{UV analysis}

The synthesized AgNPs were confirmed by UV-visible spectroscopy $[5,13]$. Figure 1 confirms the formation of AgNPs. The peak for AgNPs was observed at 448 $\mathrm{nm}$. Green synthesis of AgNPs with an aqueous extract of Ipomoea pes-caprae leaves also gave the similar UV spectrum [22]. Formation of AgNPs was confirmed visually from the color change after the addition of Ipomoea pes-caprae extract into silver nitrate solution. The formation of silver nanoparticle was due to surface plasmon resonance (SPR) [23]. In UV-visible spectrum, the shift for the AgNPs was observed due to the presence of secondary metabolites such as Ergoline alkaloids, Indolizidine alkaloids, Benzenoids and Phenolic compounds in the plant extract [24].

The stability of silver nanoparticles is confirmed by

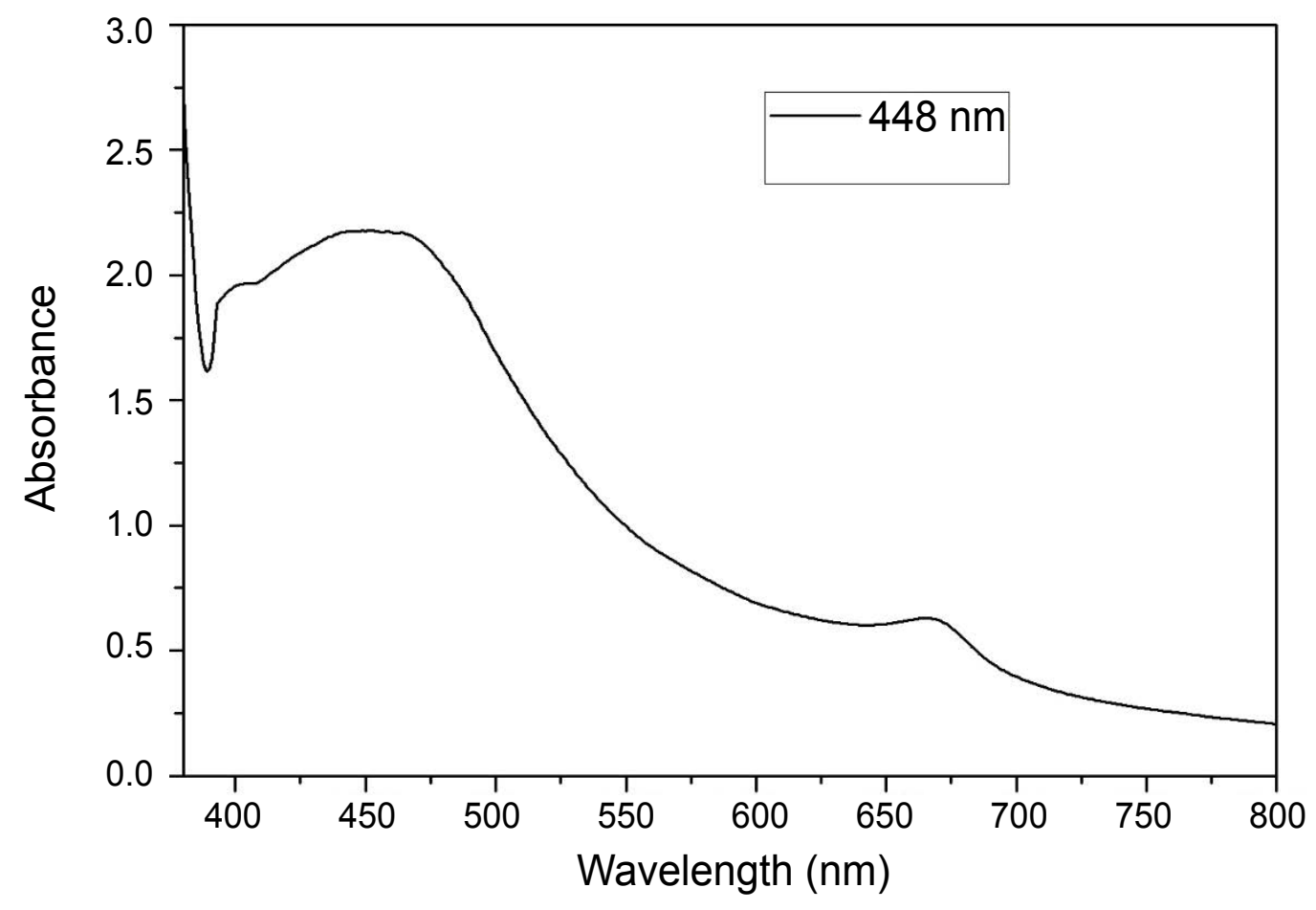

Figure 1: UV-Visible spectrum of synthesized AgNPs. 


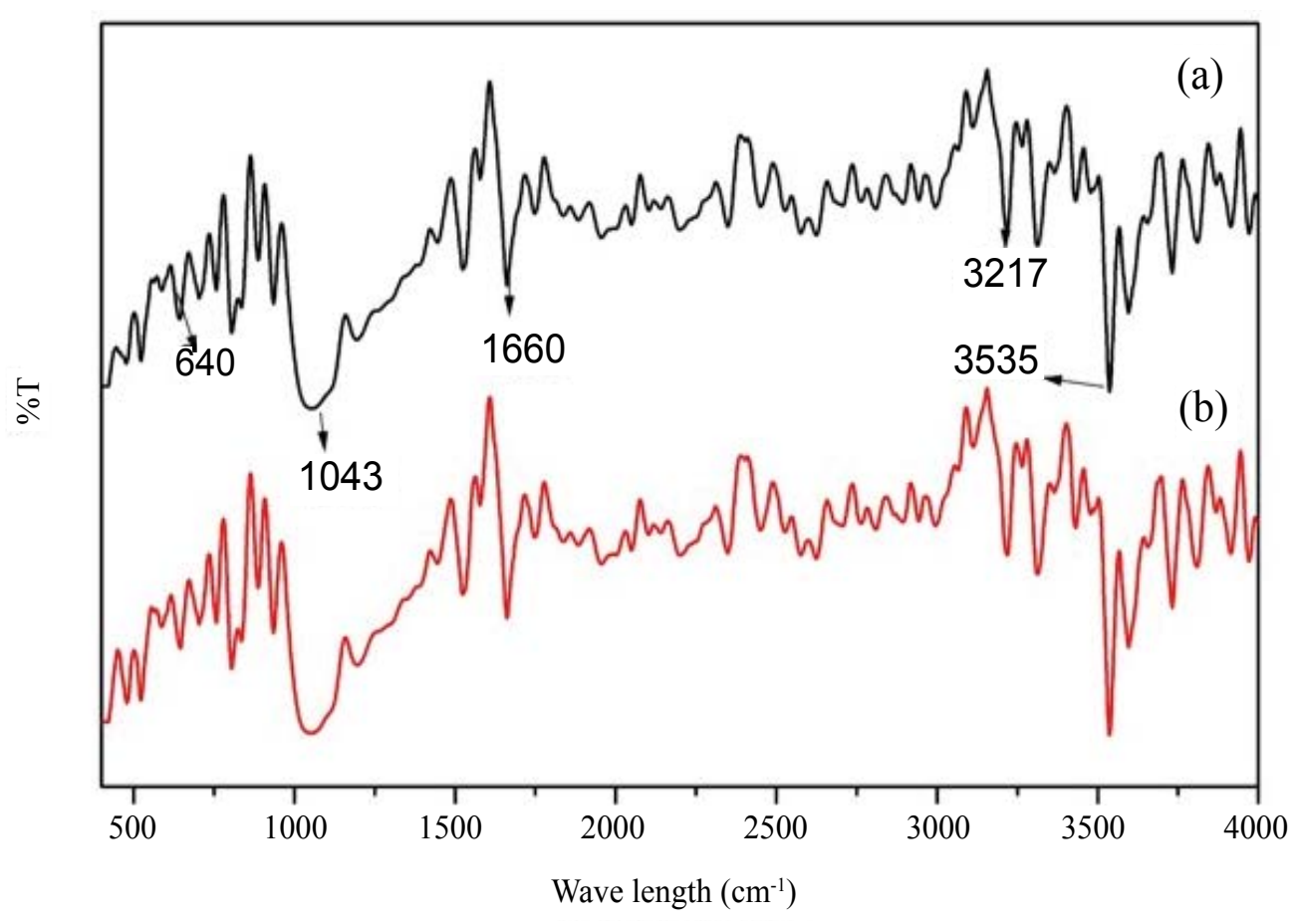

Figure 2: FTIR spectra of (a) Stem Extract of Ipomoea pes-caprae and (b) Synthesized AgNPs.

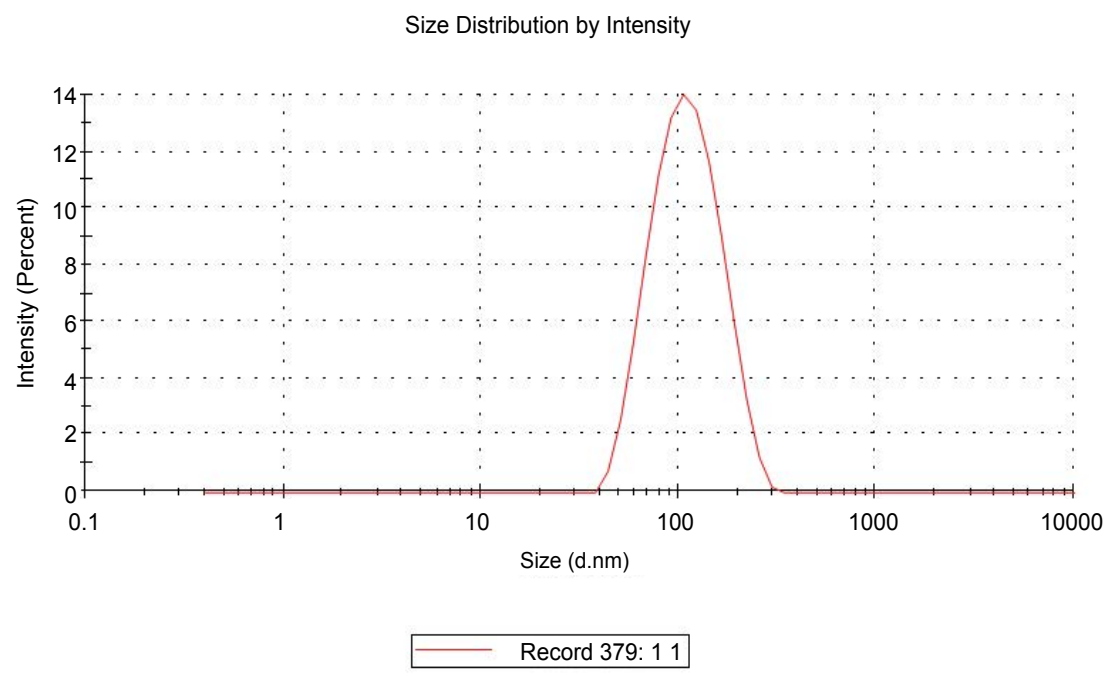

Figure 3: Particle size distribution.

Surface Plasmon Resonance (SPR) which is a strong absorption of usually metal nanoparticles in the visible range. In this case, silver nanoparticles synthesized via this method shows at a peak at $448 \mathrm{~nm}$ and formed as a yellowish brown colour in the solution confirming that the excitement in Ultra-Visible range depends on the size of the particles. This SPR phenomenon of silver nanoparticles arises due to irradiation of AgNP with visible light [25].

\section{FTIR investigation}

Figure 2 shows the synthesized AgNPs and the plant extract analyzed by FTIR. The secondary metabolites in the extract were responsible for the reduction and stabilization of AgNPs and observed FTIR spectrum. The peaks observed in FTIR spectrum of AgNPs are 640,
$3535,3217,1660,1043 \mathrm{~cm}^{-1}$. At peak $1660 \mathrm{~cm}^{-1}$ it represents the $\mathrm{C}=\mathrm{C}$ stretch vibration and it corresponds to the amide I bond from protein. The peak at $1043 \mathrm{~cm}^{-1}$ shows $\mathrm{C}-\mathrm{O}$ stretch of $(\mathrm{CH}-\mathrm{OH})$ in cyclic alcohol. The peak at $640 \mathrm{~cm}^{-1}$ corresponds to the aromatic $\mathrm{C}-\mathrm{H}$ vibrations that denotes the involvement of free quinone (polyphenolic compounds) in the extract [26]. It confirms the polyphenolic compounds from the Ipomoea pes-caprae contributing as a reducing and capping molecule for $\mathrm{Ag}$ NPs. The peak at $2004 \mathrm{~cm}^{-1}$ confirms a match with the $\mathrm{C}=\mathrm{O}$ amide stretching. It implies the presence of several functional groups in the aqueous leaf extract and $\mathrm{Ag}$ NPs. Notably, AgNPs were formed by biotransformation of silver ions with plant polyphenols or polysaccharides in the extract. 


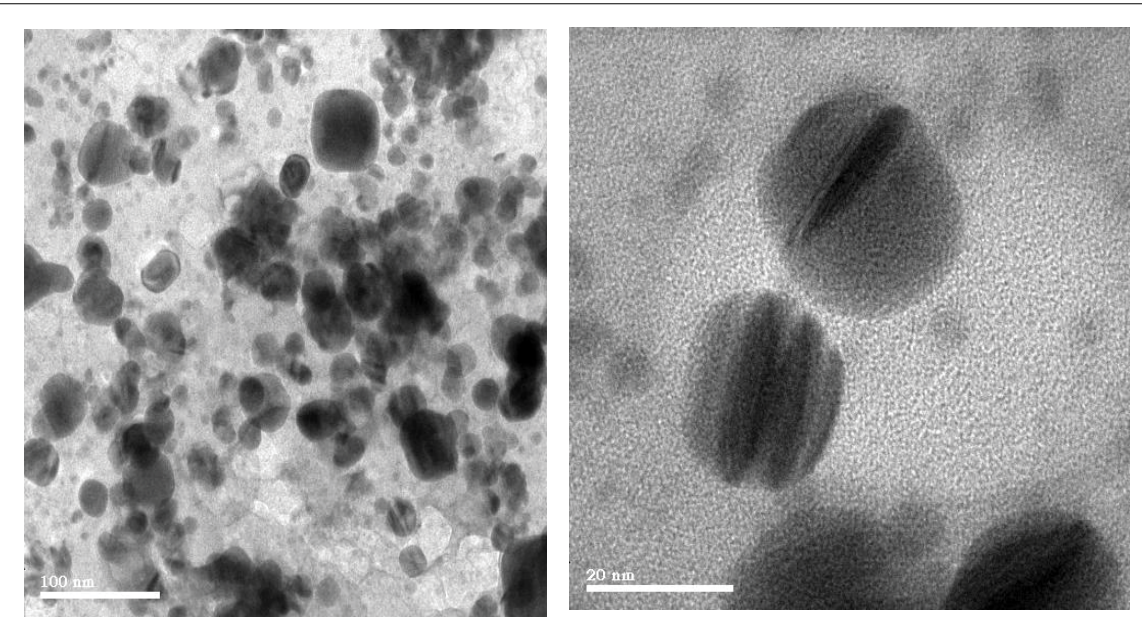

Figure 4: TEM images of synthesized AgNps.

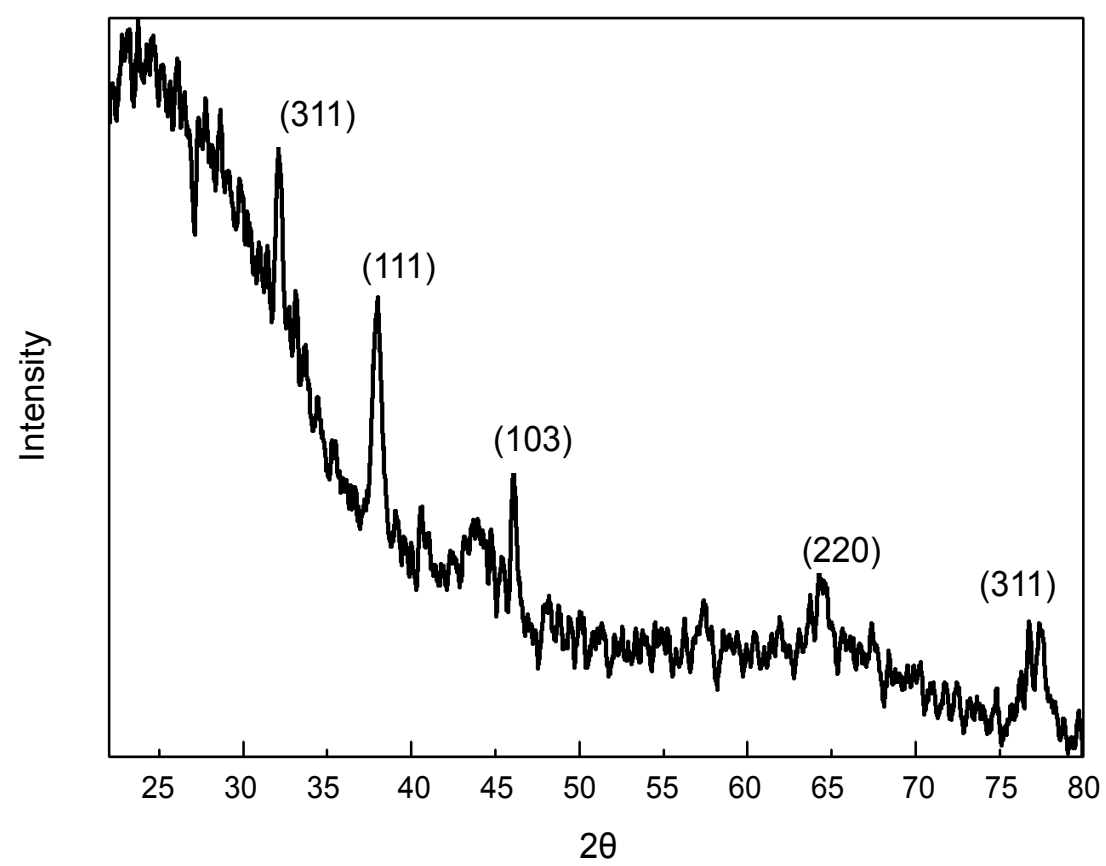

Figure 5: X-Ray Diffractogram of synthesized AgNPs.

\section{Particle size distribution}

The average size of the particles, size distribution, and polydispersity index (PDI) of AgNPs was determined by a particle size analyzer and the obtained results are shown in Figure 3. The average particle diameter of AgNPs is $116 \mathrm{~nm}$ and Polydispersity index is 0.264 . The same particle size and PDI of AgNPs with the highly monodispersed were reported by Kajal and Misra [27]. These particles were in the range of 50 to $100 \mathrm{~nm}$. Bio-active molecules in the Ipomoea pes-caprae stem extract were also responsible for the stability of the AgNPs for a prolonged exposure. Similarly, Observing TEM micrograph, AgNPs were also non-agglomerated.

\section{Transmission Electron Microscope (TEM)}

Figure 4 confirm the size and shape of the AgNPs and are not agglomerated, well-dispersed with spherical shape. The average particle size of the AgNPs is highly influenced by the concentration of stem extract of Ipomoea pes-caprae. If the concentration of stem extract is further increased in the reaction, then the particle size will be decreased. The synthesized particles were in nano size with smooth surface [4]. Figure $4 \mathrm{~b}$ shows the synthesized nanoparticles not agglomerated and separated from each other. AgNPs synthesized from Ipomoea pes-caprae stem extract were mostly less than $100 \mathrm{~nm}$.

\section{X-ray diffraction}

Figure 5 shows XRD patterns of AgNPs synthesized using Ipomoea pes-caprae stem extract. The XRD patterns of AgNPs confirms face cubic center (FCC) [28]. The XRD peaks attributed to the crystallographic planes [29] and peaks at $2 \theta$ of $46^{\circ}, 32^{\circ}, 34^{\circ}$ and $64^{\circ}$ representing (1 03 ), (1 11 1), (2 20 ) and (3 11 1) Bragg's reflections of FCC structure of silver. XRD result AgNPs synthesized from Ipomoea pes-caprae stem extract were crystalline.

\section{Anti-microbial potential of AgNPs}

The antibacterial activity of the green synthesized 


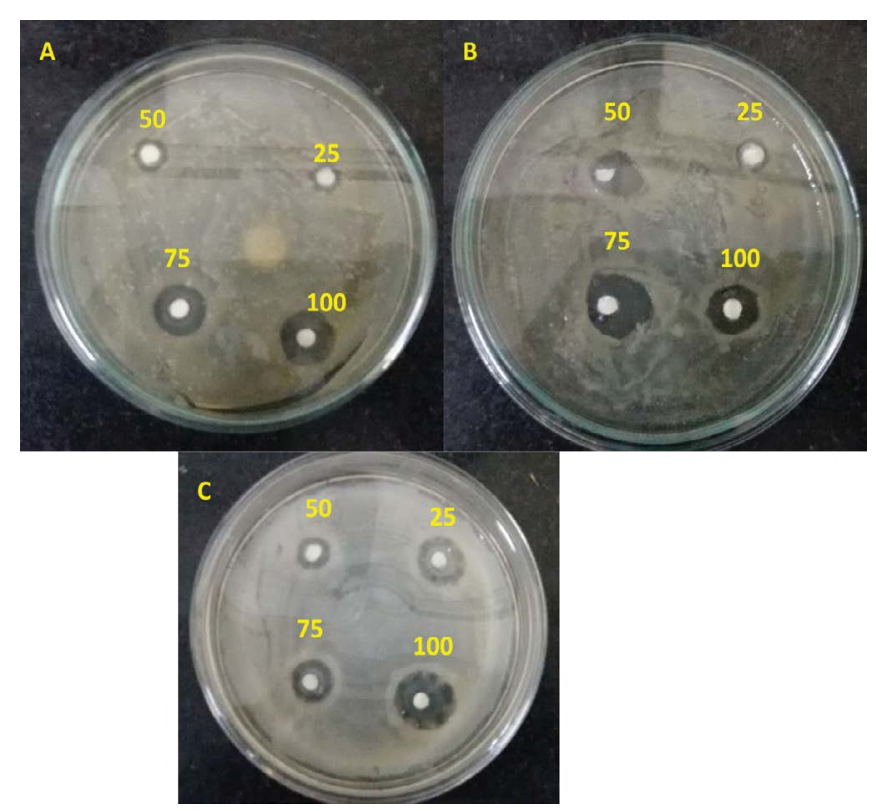

Figure 6: Zone of Inhibition by Silver Nanoparticles A) P. aeruginosa B) Bacillus and C) E. coli.

Table 1: Zone of inhibition ( $\mathrm{mm}$ ) for green synthesized AgNPs from Ipomoea pes-caprae.

\begin{tabular}{|l|l|l|l|l|}
\hline Clinical Isolates & \multicolumn{4}{l}{ AgNPs $(\boldsymbol{\mu g})$} \\
\cline { 2 - 5 } & $\mathbf{2 5}$ & $\mathbf{5 0}$ & $\mathbf{7 5}$ & $\mathbf{1 0 0}$ \\
\hline P. aeruginosa & $6 \pm 1$ & $8 \pm 2$ & $10.1 \pm 1$ & $13 \pm 2$ \\
\hline E. coli & $7 \pm 2$ & $9 \pm 1$ & $12 \pm 1$ & $19 \pm 2$ \\
\hline Bacillus & $4 \pm 1$ & $4.59 \pm 1$ & $7 \pm 1$ & $14 \pm 1$ \\
\hline
\end{tabular}

AgNPs with size range from 50 to $100 \mathrm{~nm}$ shows a broad spectrum against gram positive and negative bacteria such as Escherichia coli E. coli (-), Pseudomonas aeruginosa (P. aeruginosa (-)), Bacillus ( \pm ). The size and shape of AgNPs influence its bactericidal efficacy. Notably, green synthesized AgNPs inhibit/control the bacterial multiplication even in the clinical isolates strains which are multidrug resistant. AgNPs shows dose-dependent inhibition on bacterial growth. The mechanism of antimicrobial action of AgNPs is binding with disulphide (S-S) groups in the bacterial cell membrane, metabolic enzymes and phosphate groups present in the respiratory reactions resulting inhibiting its growth. During synthesis of AgNPs, it capped with the stem extract of Ipomoea pes-caprae that contains flavonoids boosting antimicrobial potential of AgNPs. The zone of inhibition for clinical isolates treated with AgNPs are summarized in Table 1. AgNPs synthesized from stem extract of Ipomoea pes-caprae shows greater bactericidal effect than that of the AgNPs synthesised from the leaf and root part extracts of Ipomoea pes-caprae [30].

Silver nanoparticles are capable for producing potent antimicrobial action against numerous pathogens and are being used in the therapeutics. The minimum inhibitory concentration of silver nanoparticles synthesized via greener approach with a support of an extract of G. Birdiae (GB) showed $150 \mu \mathrm{g}$ against S. aureus and around $75 \mu \mathrm{g}$ against $E$. coli. The MIC of AgNP was higher than plain silver solution and this plant extract. The MIC of silver nitrate solution against $S$. aureus and $E$. coli are $125 \mu \mathrm{g}$ and $62.5 \mu \mathrm{g}$ respectively and the MIC of this plant extract against these microbes are greater than $125 \mu \mathrm{g}$ [31].

These informed that the size and sphericity of silver nanoparticles could facilitate potential antimicrobial against bacterial pathogens. The size of the AgNP indirectly controls the antimicrobial action and small size AgNP could penetrate and permeate easily the cell walls of the bacterium easily and produce antimicrobial activity [32].

It is confirmed that small size of AgNP provided relatively large contact areas (for example spherical nanoparticles) showed greater antimicrobial against bacteria, comparing with large size particles [33]. The silver nanoparticles synthesized with this plant extract shows significant zone of inhibition at a concentration of $100 \mu \mathrm{g}$ against $P$. aeruginosa, E. coli and Bacillus. It is indirectly confirmed that the MIC of AgNP would be around $100 \mu \mathrm{g}$. The results confirmed that the antibacterial potential of AgNPs against $E$. coli was higher than those against $P$. aeruginosa and Bacillus. This finding might to differences in the composition of the cell wall between Gram-positive and Gram-negative bacteria. Figure 6 shows the zone of inhibition against pathogens and the anti microbial action produced by silver nano-particles.

\section{MTT assay}

The synthesized AgNPs from the stem extract of Ipomoea pes-caprae were spheres with the size of 50 $\mathrm{nm}$. Investigation were carried out using the AgNPs on human breast cancer (MCF-7) cell lines. The stem extract of Ipomoea pes-caprae on the surface of $\mathrm{Ag}$ NPs were against the cancer cells. AgNPs induce DNA damage via generating reactive oxygen species (ROS). Ipomoea pes-caprae on MCF-7 breast cancer cells provides an evidence for its anti-proliferative action, AgNPs 
shows the best result when compare to previous studies Orecchioni, et al. [29], Sondi, et al. [34], Zheng, et al. [35]. The anti-proliferative activity depends on the size and shape of the AgNPs. These shape-dependent behaviors of AgNPs allows for therapeutic applications. Certain non-regular shape AgNPs can easily absorb into various proteins and DNA promoting biological activity and apoptosis through fragmentation of DNA, cell cycle arrest at G2/M phase and then, through activation of caspase 3. AgNPs might also alter the membrane structure by binding to the Sulphur containing proteins in the cell membrane resulting destructing the cell membrane of the bacteria $[34,35]$.

Silver nanoparticles have a potential lethal effect on the cancerous cell wall. The water soluble organic moieties on the surface of the nanoparticles induce a synergistic pharmacology action such as anti-proliferative effect in various cancer cell lines, thus prove to be useful in various types of cancer treatment [36].

Silver nanoparticles could induce the apoptotic pathway in vitro via free oxygen radical generation, resulting antitumor, anti-proliferative and anti-angiogenic effects in-vitro [37]. The bioactive compounds in the plant extract possess antiangiogenic potential via abnormally expressing signaling proteins, such as Ras and AKT, subsequently, exhibit a reliable antitumor effect [38].

Silver nanoparticles have antiproliferative potential

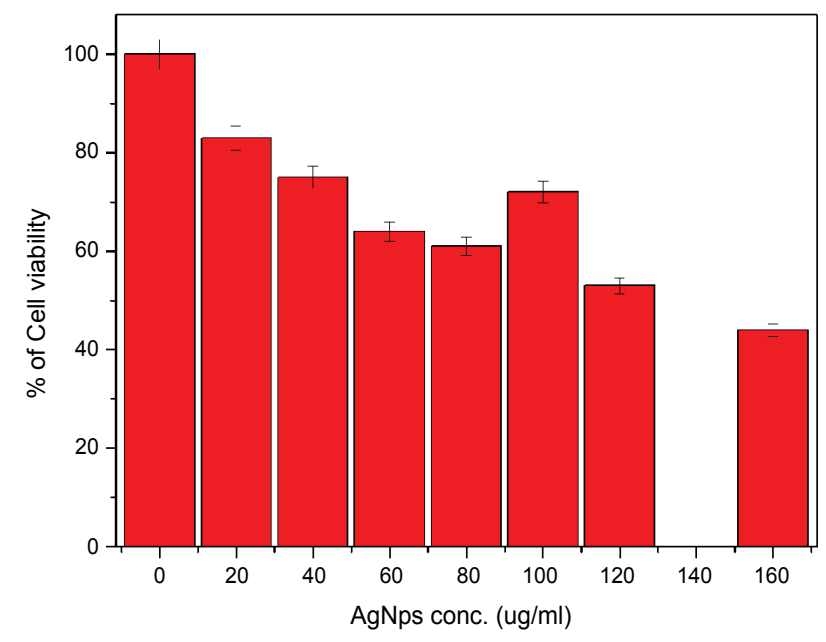

Figure 7: Statistical representation of cell viability assay.

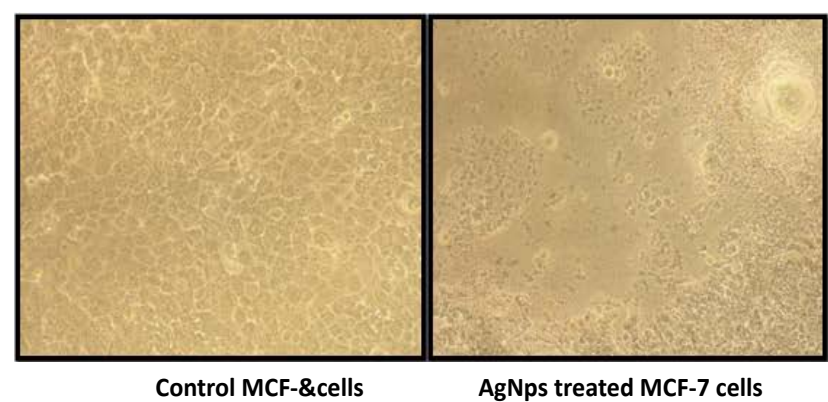

Figure 8: Images of (a) Control MCF cells (b) AgNps treated MCF cells. against human glioblastoma cells [39]. However, Nano silver acts on normal cell resulting disruption of cellular membrane and its integrity via expressing numerous signaling genes for apoptosis in mammalian cells. Therefore, cell death is programmed [40].

Apoptosis in murine embryonic fibroblast cells (NIH 3T3) was induced by nanosilver. As a consequence, the reactive oxygen species were formed by the activation of the c-Jun $\mathrm{N}$-terminal kinase pathway, leading to mitochondria-dependent apoptosis [41]. Silver nanoparticles possess anticancer activity against some of the human cancer cell lines for example colon carcinoma (HCT-116), breast carcinoma (MCF-7), liver carcinoma (Hep-G2), and intestinal carcinoma [42]. The cytotoxicity of nanosilver is interaction of silver ions with the functional groups of intracellular proteins, and the nitrogen bases and phosphate groups of DNA [43].

Silver nanoparticles play as antitumor agents by decreasing progressive development of tumor cells. AgNP inhibits forming cancer cells via blocking several signaling cascades. AgNP cytotoxic to cancer cells and hinders tumor progression without lethality to normal cells. The anti-cancer activity of biosynthesized silver nanoparticle can be produced by apoptosis via numerous cellular pathway. The pathway for Ag NP acting on the cancerous cells remain obscure.

Recent reports revealed on the size and shape dependent mechanism of AgNPs with bacterial cells play an important role against bactericidal [44]. AgNPs synthesized from Ipomoea pes-caprae stem extract provides the best result showing cytotoxic effects at IC 50 values of $78 \mu \mathrm{g} /$ $\mathrm{ml}$ (Figure 7 and Figure 8). Therefore, all experiments were performed by taking higher and lower concentration of synthesized silver nanoparticles. The complete hazard associated with the nanoparticle exposure and the molecular mechanisms of AgNPs toxicity are yet to know.

\section{Conclusion}

AgNPs from Ipomoea pes-caprae stem extract was successfully synthesized and characterized by UV-visible and FTIR spectrometers confirming the formation of AgNPs. The stability of AgNP via plant-based biosynthesis is a challenging task and it could be enhanced by the coating of bioactive molecules in the plant extract. The stability of AgNP can be assumed thro coating of bioactive molecules in the plant extract on the surface of AgNP and it is not confirmed through our experiments. The shelf life of AgNP is not evaluated in this work due to less availability of sample. The antimicrobial efficacy of the AgNP controls by size, shape, stability and concentration. We achieved the size of AgNP $50 \mathrm{~nm}$ and a maximum of $100 \mathrm{~nm}$ confirming less stability of synthesized AgNP which is a challenging task and it can improve in future work. To investigate the oxidation potential of green synthesised silver nanoparticles, $X$-ray photoelectron spectroscopy can be considered as future research. 
Metabolites like benzenoids with the functional group of alcohols, aldehydes, ketones, amines and carboxylic acids were found abundant in the Ipomoea pescaprae stem extract and responsible for bio-reduction of silver nitrate solution into nanoparticles. AgNPs were crystalline, FCC structure and its size less than $100 \mathrm{~nm}$ with spherical shape. The bio-active molecules covered on AgNPs shows anti-proliferative action against the human breast cancer cell and antimicrobial potential against clinical isolates, suggesting AgNPs could be an alternative chemotherapeutic and antimicrobial agent. AgNPs via green synthesis with this stem extract functionalize by capping/coating of bioactive molecules increasing its potential and further use in developing drug delivery and targeting.

\section{References}

1. Bhattacharya R, Mukherjee $P$ (2008) Biological properties of "naked" metal nanoparticles. Adv Drug Deliv Rev 60: 1289-1306.

2. Lara $\mathrm{HH}$, Ayala-Nunez NV, Ixtepan-Turrent L, Rodriguez-Padilla C (2010) Mode of antiviral action of silver nanoparticles against HIV-1. J Nanobiotechnology 8: 1.

3. Sun RW, Rong C, Chung NPY, Ho CM, Lin CLS, et al. (2005) Silver nanoparticles fabricated in hepes buffer exhibit cytoprotective activities toward hiv-1 infected cells. Chem Commun (Camb) 28: 5059-5061.

4. Goldberg M, Langer R, Jia X (2007) Nanostructured materials for applications in drug delivery and tissue engineering. J Biomater Sci Polym Ed 18: 241-268.

5. Prabhu D, Arulvasu C, Babu G, Manikandan R, Srinivasan P (2013) Biologically synthesized green silver nanoparticles from leaf extract of vitex negundo L. induce growth-inhibitory effect on human colon cancer cell line HCT15. Process Biochemistry 48: 317-324.

6. El Badawy AM, Scheckel KG, Suidan MT, Tolaymat TM (2012) The impact of stabilization mechanism on the aggregation kinetics of silver nanoparticles. Sci Total Environ 429: 325-331.

7. Liz-Marzan LM, Lado-Tourino I (1996) Reduction and stabilization of silver nanoparticles in ethanol by nonionic surfactants. Langmuir 12: 3585-3589.

8. Esumi K, Tano T, Torigoe K, Meguro K (1990) Preparation and characterization of biometallic palladium-copper colloids by thermal decomposition of their acetate compounds in organic solvents. Chem Mater 2: 564-567.

9. Pileni MP (2000) Fabrication and physical properties of self-organized silver nanocrystals. Pure Appl Chem 72: 5365.

10. Sun YP, Atorngitjawat P, Meziani MJ (2001) Preparation of silver nanoparticles via rapid expansion of water in carbon dioxide microemulsion into reductant solution. Langmuir 17: $5707-5710$

11. Henglein A (1993) Physicochemical properties of small metal particles in solution: Microelectrode reactions, chemisorption, composite metal particles, and the atom-tometal transition. J Phys Chem 97: 5457-5471.

12. Henglein A (1998) Colloidal silver nanoparticles: Photochemical preparation and interaction with $02, \mathrm{ccl} 4$, and some metal ions. Chem Mater 10: 444-446.
13. Henglein $A$ (2001) Reduction of $A g(C N)_{2}$ - on silver and platinum colloidal nanoparticles. Langmuir 17: 2329-2333.

14. De Souza MM, Madeira A, Berti C, Krogh R, Yunes RA, et al. (2000) Antinociceptive properties of the methanolic extract obtained from ipomoea pes-Caprae(L.). R. Br. J Ethnopharmacol 69: 85-90.

15. Pongprayoon $U$, Baeckstrom $P$, Jacobsson $U$, Linstrom M, Bohlin L (1992) Antispasmodic activity of beta-damascenone and E-phytol isolated from ipomoea pes-caprae. Planta Med 58: 19-21.

16. Pereda-Martiez, Escalante-Sanchez E, Escobedo-Martínez C (2005) Chacterization of lipophilic penta saccharides from beach morning glory (Ipomoea pes-caprae). J Nat Prod 68: 226-230.

17. Ashish Manigaunha, Ganesh N, Kharya MD (2010) Morning glory: A new thirst in-search of de-novo therapeutic approach. Int J Phytomedicine 2: 18-21.

18. Umamaheshwari G, Ramanathan $T$, Shanmugapriya $R$ (2012) Antioxidant and radical scavenging effect of Ipomoea pes-caprae Linn. R.Br. Int J PharmTech Research 4: 1177-1180.

19. Manigauha A, Kharya MD, Ganesh N (2015) In vivo antitumor potential of Ipomoea pes-caprae on melanoma cancer. Pharmacognosy Magazine 11: 426-433.

20. Subha V, Ernest Ravindran RS, Hariram J, Renganathan $S$ (2015) Bioreduction of silver nanoparticles from aqueous stem extract of catharanthus roseus and bactericidal effects. Asian J Pharm Clin Res 8: 116-119.

21. Slater TF, Sawyer B, Sträuh U (1963) Studies on succinate-tetrazolium reductase systems: III. Points of coupling of four different tetrazolium salts III. Points of coupling of four different tetrazolium salts. Biochim Biophysics Acta 77: 383-393.

22. Subha V, Ernest Ravindran RS, Sruthi $P$, Renganathan S (2015) An eco-friendly approach for synthesis of silver nanoparticles using ipomoea pes-caprae root extract and their antimicrobial properties. Asian J Pharm Clin Res 8: 103-106.

23. Mirshahi T, Irache JM, Nicolas C, Mirshahi M, Faure JP, et al. (2002) Adaptive immune responses of legumin nanoparticles. J Drug Target 10: 625-631.

24. Nadkarni KM (2006) Indian plants and drugs with their medicinal properties and uses. ( $5^{\text {th }}$ edn), Asiatic Publishing House, India.

25. Mock J J, Barbic M, Smith D R, Schultz D A, Schultz S (2002) Localized surface plasmon resonance effects by naturally occurring chinese yam particles. J Chem Phys 116: 6755.

26. Krishanan R, Maru GB (2006) Isolation and analyses of polymeric polyphenols fractions from black tea. Food Chemistry 94: 331-340.

27. Kajal H, Misra A (2011) Preparation of tetanus toxoid and ovalbumin loaded gliadin nanoparticles for oral immunization. J Biomed Nanotechnol 7: 211-212.

28. Saxena A, Sachin K, Bohidar HB, Verma AK (2005) Effect of molecular weight heterogeneity on drug encapsulation efficiency of gelatin nano-particles. Colloids Surf B Biointerfaces 45: 42-48.

29. Orecchioni AM, Duclairoir C, Irache JM, Nakache E (2007) Plant protein-based nanoparticles. Nanotechnologies for the Life Sciences. Wiley-VCH Verlag GmbH \& Co, Germany. 
30. Satyavani K, Gurudeeban S, Ramanathan T, Balasubramanian T (2013) Ipomoea pes-caprae mediated silver nanoparticles and their antibacterial effect. Science international 1: 155-159.

31. Anderson Passosde Aragao, Taiane Mariade Oliveira, Patrick VerasQuelemes, Márcia Luana GomesPerfeito, Maria CarvalhoAraújo, et al. (2016) Green synthesis of silver nanoparticles using the seaweed Gracilaria birdiae and their antibacterial activity. Arabian Journal of Chemistry.

32. Hamouda T, Baker Jr JR (2000) Antimicrobial mechanism of action of surfactant lipid preparations in enteric gram-negative bacilli. J Appl Microbiol 89: 397-403.

33. Baker C, Pradhan A, Pakstis L, Pochan DJ, Shah SI (2005) Synthesis and antibacterial properties of silver nanoparticles. J Nanosci Nanotechnol 5: 244-249.

34. Sondi I, Branka Salopek-Sondi (2004) Silver nanoparticles as antimicrobial agent: A case study on $\mathrm{E}$. coli as a model for gram-negative bacteria. J Colloid Interface Sci 275: 177-182.

35. Zheng J, Wu X, Wang M, Ran D, Xu W, et al. (2008) Study on the interaction between silver nanoparticles and nucleic acids in the presence of cetyltrimethyl ammonium bromide and its analytical application. Talanta 74: 526-532.

36. Raghunandan D, Ravishankar B, Sharanbasava G, Mahesh DB, Harsoor V, et al. (2011) Anti-cancer studies of noble metal nanoparticles synthesized using different plant extracts. Cancer Nano 2: 57-65.

37. Gurunathan S, Lee KJ, Kalimuthu K, Sheikpranbabu S,
Vaidyanathan R, et al. (2009) Antiangiogenic properties of silver nanoparticles. Biomaterials 30: 6341-6350.

38. Martins D, Frungillo L, Anazzetti MC, Melo PS, Durán N (2010) Antitumoral activity of L-ascorbic acid-poly- D, L-(lactide-co-glycolide) nanoparticles containing violacein. Int J Nanomedicine 5: 77-85.

39. AshaRani PV, Low Kah Mun G, Hande MP, Valiyaveettil S (2009) Cytotoxicity and genotoxicity of silver nanoparticles in human cells. ACS Nano 3: 279-290.

40. Sanpui P, Chattopadhyay A, Ghosh SS (2011) Induction of apoptosis in cancer cells at low silver nanoparticle concentrations using chitosan nanocarrier. ACS Appl Mater Interfaces 3: 218-228.

41. Hsin YH, Chen CF, Huang S, Shih TS, Lai PS, et al. (2008) The apoptotic effect of nanosilver is mediated by a ROSand JNK-dependent mechanism involving the mitochondrial pathway in NIH3T3 cells. Toxicol Lett 179: 130-139.

42. Shawkey AM, Rabeh MA, Abdulall AK, Abdellatif AO (2013) Green nanotechnology: Anticancer activity of silver nanoparticles using citrullus colocynthis aqueous extracts. Adv Life Sci Technol 13: 60-70.

43. Sriram MI, Kanth SB, Kalishwaralal K, Gurunathan S (2010) Antitumor activity of silver nanoparticles in dalton's lymphoma ascites tumor model. Int J Nanomedicine 5: 753-762.

44. Pal S, Tak YK, Song JM (2007) Does the antibacterial activity of silver nanoparticles depend on the shape of the nanoparticle? A study of the gram-negative bacterium Escherichia coli. Appl Environ Microbiol 73: 1712-1720. 